\title{
For How Long Is Exclusive Breast-feeding Adequate to Satisfy the Dietary Energy Needs of the Average Young Baby? ${ }^{1}$
}

\author{
R. G. WHITEHEAD
}

Medical Research Council Dunn Nutrition Centre, Cambridge, United Kingdom, and Keneba, The Gambia

\begin{tabular}{|c|c|}
\hline \multicolumn{2}{|c|}{ ABSTRACT } \\
\hline $\begin{array}{l}\text { This review is based on a lecture given in connection with the } \\
1994 \text { Nutricia Foundation Award. It describes how recent re- } \\
\text { search findings in infant dietary energy requirements have pro- } \\
\text { vided a firm quantitative basis for the widely quoted pediatric } \\
\text { view that exclusive breast-feeding should provide sufficient nour- } \\
\text { ishment for the average child until } 4-6 \text { mo of age. (Pediatr Res } \\
\text { 37: } 239-243, \mathbf{1 9 9 5} \text { ) }\end{array}$ & 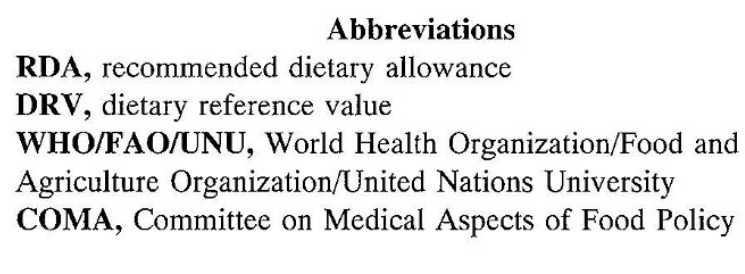 \\
\hline
\end{tabular}

Data derived using the doubly labeled water method have demonstrated that dietary energy requirements are substantially lower than they were at one time believed to be. Thus, a given daily volume of maternal milk is sufficient until an infant is substantially older. Assuming a baby is growing along the 50th National Center for Health Statistics weight percentile, current data indicate that a typical average intake of $850 \mathrm{~mL} / \mathrm{d}$ would satisfy the energy requirements of an infant until $4 \mathrm{mo}$. Because the average healthy baby in the Third World tends to be smaller than its European counterpart and grows along the 25th percentile rather than the 50th, this period is theoretically extended to $6 \mathrm{mo}$. With previous calculations of this type, based on estimates of energy requirements such as those published by the World Health Organization/Food and Agriculture Organization in 1973, it was difficult to justify an estimated 2-3 mo exclusive lactational practice.

Nutrition is now recognized as being a key component in virtually every aspect of health, and thus a nutritional scientist tends to become involved in many research topics during the course of a career. This has certainly been so in my own case, but none of the things I have worked on have been more important to me than the diet and well-being of the young baby. With some trepidation, I have decided to relate, for this special Nutricia lecture, my involvement over the years in a scientifically complex and emotionally charged topic: For how long one can reasonably expect the breast milk output of the

Received April 28, 1994; accepted September 12, 1994.

Correspondence: Dr. R. G. Whitehead, Dunn Nutrition Centre, Downhams Lane, Milton Road, Cambridge CB4 1XJ, UK.

${ }^{1}$ This presentation was given during receipt of the Nutricia Foundation Award. average mother to meet completely the dietary energy needs of the average baby?

The word average is emphasized because there is a marked variance around both parameters. This distribution can be as high as $\pm 50 \%$. It is reasonable to postulate, however, that there is a significant quantitative interaction between these variables. At a given age, the more milk a baby needs the more he or she will try to take from the mother. This is why we routinely find higher intakes of breast milk in bigger babies than in smaller ones, and for similar reasons why the average female baby tends to consume less milk for her age than a male counterpart (1).

One of the original incentives during the 1970s for my interest in this subject was to try to clear up an enigma that I was finding increasingly worrying. As a member of various national and international committees on infant feeding, I had been responsible for furthering the perfectly reasonable view that exclusive breast-feeding should be sufficient to meet the nutritional needs of the average baby until at least the beginning of the fourth month of life. At the same time, I was also a member of other committees concerned with defining RDA for dietary energy and nutrients. The trouble was that the RDA recommendations $(2,3)$, being made in the 1960 s and 1970 s were not completely compatible with the breast-feeding conclusions.

This is not the only reason for my interest, however. Clarification was of major practical importance in terms of the health and well-being of the young baby. This was especially the case in the Third World, where unsanitary conditions make the too early introduction of any type of other food, either milk or solids, a potentially hazardous practice. 


\section{CALCULATIONS BASED ON PRE-1980 RDA FOR DIETARY ENERGY}

The first attempt I made to rationalize the long-term adequacy of exclusive breast-feeding was in the mid-1970s (4) and was based on the energy RDA then currently in use. I had also concluded from an examination of the published data that the milk output of the average mother probably peaked at approximately $850 \mathrm{~mL}$. In fact, this value was somewhat higher than the average in the literature (1), but I had assumed that there was likely to be a bias toward underestimation in the testweighing procedure used to measure the intake of breast milk. Another tacit assumption was that if the energy needs of a child were met on a food as perfectly balanced for human needs as breast milk it was reasonable to suppose that the requirements of the rest of the essential nutrients would be as well. Waterlow and Thomson (5) did a similar calculation based on protein RDA; our basic conclusions turned out to be very similar.

The relevant energy RDA I used were $120 \mathrm{kcal}(500 \mathrm{~kJ}) / \mathrm{kg}$ body weight $/ \mathrm{d}$ at $0-3$ mo of age and $115 \mathrm{kcal}(480 \mathrm{~kJ}) / \mathrm{kg} / \mathrm{d}$ from 4 to $6 \mathrm{mo}$. Thus, a baby growing along the mean of the male and female 50th percentiles, and weighing about $4.9 \mathrm{~kg}$ at $2 \mathrm{mo}, 5.7 \mathrm{~kg}$ at $3 \mathrm{mo}$, and $6.4 \mathrm{~kg}$ at $4 \mathrm{mo}$, would need $588 \mathrm{kcal}$ $(2460 \mathrm{~kJ}) / \mathrm{d}, 655 \mathrm{kcal}(2740 \mathrm{~kJ}) / \mathrm{d}$, and $736 \mathrm{kcal}(3080 \mathrm{~kJ}) / \mathrm{d}$, respectively. If one also assumed the generally accepted average breast milk energy content at that time of $70 \mathrm{kcal}(293$ $\mathrm{kJ}) / 100 \mathrm{~mL}, 850 \mathrm{~mL}$ of milk would supply only about $600 \mathrm{kcal}$ $(2510 \mathrm{~kJ})$, barely enough for a 2 -mo-old child.

Clearly, something was wrong. Either official advice that exclusive breast-feeding was adequate to cover the average child's needs until at least 4 mo was in fact erroneous, breast milk intake values in the literature including our own were extremely inaccurate, or our estimates of the energy needs of young babies were faulty. Shedding light on this embarrassing gap in our knowledge was to lead to some exciting and novel investigations by my colleagues and myself during the next few years.

\section{MEASURING BREAST MILK INTAKE BY WATER TURNOVER}

Perhaps I ought to say at the start that we regarded a 2-mo limit to the adequacy of exclusive breast-feeding to be a rather unlikely explanation. There were ample data testifying that the average healthy baby fed in this way showed few signs of significant growth faltering until the fourth month at the earliest. Of the remaining alternatives, the breast milk intake values were the primary suspect. Test weighing is potentially full of errors, especially when working with babies truly being fed on demand. In Third World countries, for example, the frequency that a child is put to the breast can be as often as 20 times per day. One is therefore faced with trying to measure before and after weight increments averaging only $43 \mathrm{~g}$. Clearly, we had to develop a completely new approach. Furthermore, it was important that any new method did not cause undue interference with customary feeding patterns and normal mother-baby interactions.

Techniques involving the measurement of total body water turnover rate had previously been used in suckling animals (6) but not in breast-fed human babies because of the hazards inherent in the use of radioactively labeled water. By the end of the 1970s, however, sensitive mass spectrometer techniques were beginning to allow the measurement of low levels of enrichment with nonradioactive stable isotopes, and this was the approach Dr. W. A. Coward decided to adopt. The resultant technique (7) required that the baby only had to be given a small oral dose of water labeled with deuterium $\left({ }^{2} \mathrm{H}_{2} \mathrm{O}\right)$, followed by the collection of small saliva samples regularly over the next 11-14 d. The rate at which the deuterium in the enriched body fluids became diluted to background levels was directly proportional to the volume of milk intake.

This initial technique was only suitable for the youngest babies who were being exclusively breast-fed, but it did give a value for breast milk intake averaged over a representative 14-d period. Such a time span had been totally impossible to achieve with test weighing. Later Orr-Ewing et al. (8) enhanced Coward's technique by developing a second procedure in which the stable isotope was given to the mother. This allowed accurate measurements of breast milk intake to be achieved even in older babies fed a variety of solids and liquids. This second method is mathematically more complex and involves extra samples, however, and for studies in which one can be sure that no other foods or water have been given, the simpler technique (7) is adequate.

When we analyzed breast milk intakes using the new method, it soon became apparent, much to our surprise, that our previous estimates based on the test-weighing procedure, after making the allowance for possible underestimation, were unlikely to have been extremely inaccurate. An average intake of $850 \mathrm{~mL} / \mathrm{d}$ remained a reasonable representative value. It thus became necessary to switch our focus toward energy requirements. Had we been assuming these to be much higher than they really were?

\section{APPRAISAL OF EARLIER ESTIMATES FOR ENERGY NEEDS OF YOUNG BABIES}

I first became involved in questioning the energy recommendations for young babies, which had been in force for many decades, in connection with the COMA discussions that led up to the 1979 revision of the Recommended Daily Amounts Report (9). It was argued that if daily milk intakes truly did average approximately $850 \mathrm{~mL} / \mathrm{d}$ there was no way that dietary energy needs at 3 mo could be as high as 115-120 kcal $(480-500 \mathrm{~kJ}) / \mathrm{kg} / \mathrm{d}$. On the basis of this teleologic reasoning, it was decided to decrease the recommendation to $100 \mathrm{kcal}(420$ $\mathrm{kJ}) / \mathrm{kg}$ at $3 \mathrm{mo}$ and continue it at this level for the rest of infancy.

It might be asked "Why not less than $100 \mathrm{kcal}$ after 3 mo?" It was obvious that $850 \mathrm{~mL}$ of milk would not satisfy this amount at, for example, 4 mo. This question enables me to make a general philosophical point that I learned early in my "RDA career." In committees, it is essential to adopt a prudent approach and when in doubt to err on the side of caution. When one is dealing with the sensitive issue of making recommendations for the feeding of very young babies, the need to be cautious is even greater. Even so, we introduced a $10-15 \%$ cut 
in dietary energy allowances for infancy. In 1979 this seemed revolutionary, but the breast-feeding advice/RDA enigma remained.

My next theoretical foray into this subject was again in connection with an RDA committee, this time the one that led to the $1985 \mathrm{WHO} / \mathrm{FAO} / \mathrm{UNU}$ report $(10)$ on energy and protein needs. John Waterlow was the chairman, and he asked Alison Paul and me to carry out a critical appraisal of the current literature on the food energy intakes of healthy infants and toddlers living in western-style industrialized countries. The now well-known result (11) was the graph reproduced in Figure 1. From these data, it was readily apparent that few populations of babies appeared to be eating at the assumed dietary energy requirement level, and a subsequent analysis showed that it was the children who started life being breastfed who consumed the least (12).

To rationalize this rather complex distribution of data, the data were subjected to quadratic multiple regression analysis (11). The analysis indicated that during the first few months of life there was a much steeper fall in energy requirements when reduced to a per $\mathrm{kg}$ body weight basis than had previously been supposed. At $3 \mathrm{mo}$, for example, the predicted energy need was no more than $95 \mathrm{kcal}(400 \mathrm{~kJ}) / \mathrm{kg}$, and by 4 mo it was $90 \mathrm{kcal}$ $(360 \mathrm{~kJ})$. In the case of breast-fed children, the estimated average energy values were lower still.

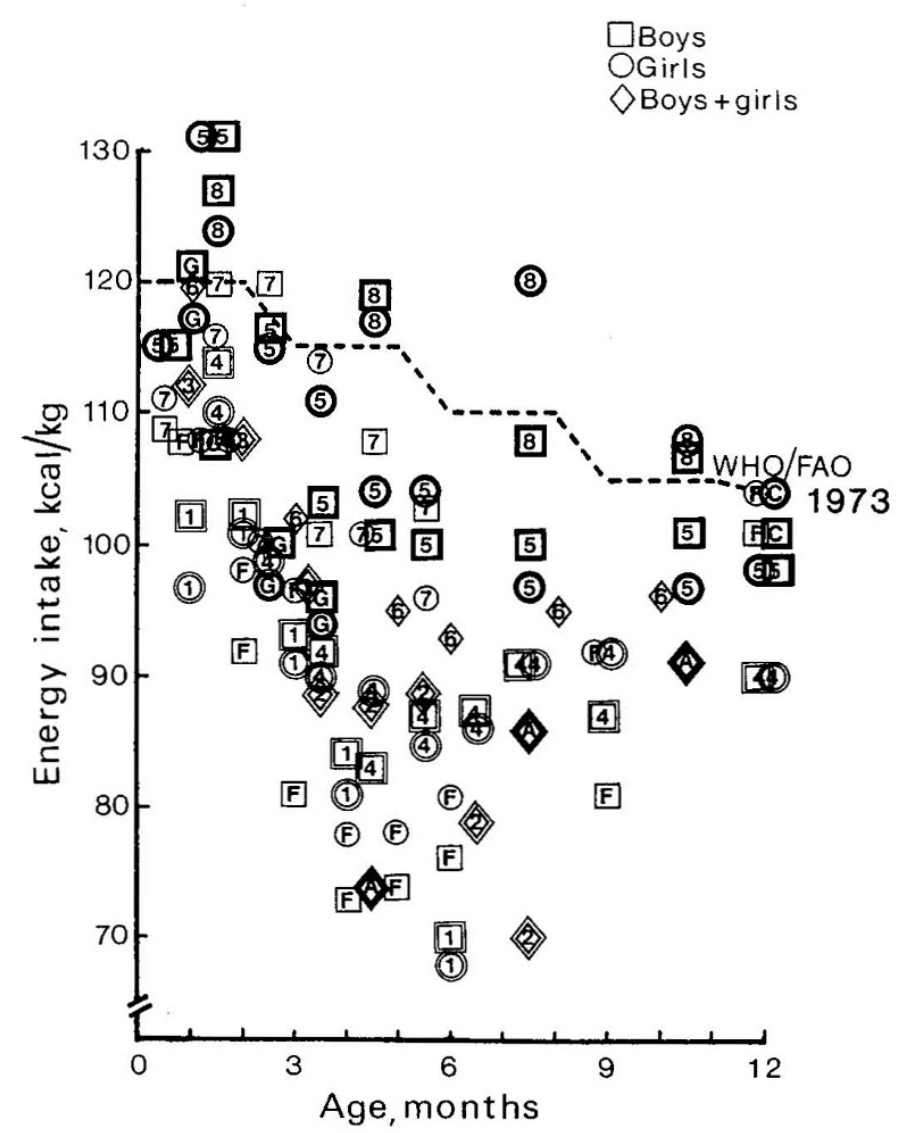

Figure 1. The energy intakes per $\mathrm{kg}$ body weight of boys and girls in the first year of life compared with WHO/FAO 1973 recommendations (11). The numbers and letters for the data points relate to references in the original publication.
This analysis was then reviewed by the WHO/FAO/UNU advisory committee responsible for revising the energy and protein requirements report. It was generally accepted that previous values for energy requirements probably had been set too high, but the committee was worried about accepting values that would represent a $25 \%$ drop by 3-4 mo. It was consequently decided to compromise on $109 \mathrm{kcal}(450 \mathrm{~kJ}) / \mathrm{kg} / \mathrm{d}$ at 2-3 mo, $103 \mathrm{kcal}(430 \mathrm{~kJ})$ at 3-4 mo, and $99 \mathrm{kcal}(415 \mathrm{~kJ})$ at 4-5 mo. One of the reasons was the same as already described in connection with the 1979 COMA panel (9): the importance of being cautious when you cannot be completely sure. There was also the valid worry that calculating dietary needs solely on the basis of breast milk and weaning food intake data was far from the quantitative ideal. Unfortunately, this prudence again meant that the incongruity with breastfeeding advice still existed.

\section{DIRECT MEASUREMENT OF ENERGY NEEDS OF HEALTHY, GROWING BABIES}

In their concluding remarks, the $1985 \mathrm{WHO} / \mathrm{FAO} / \mathrm{UNU}$ committee (10) advised that future recommended energy values should be given a much firmer scientific basis and should be derived from direct measures of energy expenditure. A number of research groups in different parts of the world took up this challenge; this is why the Dunn Nutrition Centre, under Dr. Coward's overall influence, has spent so much time refining the doubly labeled water method (13) for human use.

The basic scientific principles behind the doubly labeled water method are relatively simple, although this simplicity belies some challenging underlying complexities that Dr. Coward had first to solve. Basically, the subject, in this case a baby, is given a small oral dose of tap water that has been enriched with extra stable isotopes of both oxygen and hydrogen, ${ }^{2} \mathrm{H}_{2} \mathrm{O}$ and $\mathrm{H}_{2}{ }^{18} \mathrm{O}$. These are normal constituents of water, and they rapidly equilibrate with all the different body pools of water. The hydrogen and associated deuterium gradually disappear from the body as water in excretory products. The oxygen and its heavier isotopic form do, too, but because of the intervention of the enzyme carbonic anhydrase, they also disappear as carbon dioxide, and thus levels of ${ }^{18} \mathrm{O}$ enrichment in samples of body fluids such as saliva or urine fall more quickly than ${ }^{2} \mathrm{H}$ levels.

The higher the energy expenditure, the more carbon dioxide produced and the greater the difference between the slopes of the two enrichment disappearance curves. Regression analysis on the two sets of data points derived from urine and saliva samples collected over $14 \mathrm{~d}$ or so not only produces an average energy expenditure for that period, but the variance around each regression line enables a 95\% confidence limit to be quoted as well. The value obtained covers not only resting metabolism and energy expenditure associated with activity, but also the energy used during the synthetic processes involved in growing. The only thing not measured is the intrinsic energy deposited in the new tissue itself. However, except during the first few months of life, the latter represents only a small fraction of total energy costs and an allowance for it can easily be applied. 
Before the exercise that went into the 1991 COMA British DRV Report (14) a group of us at the Dunn Nutrition Centre on the initiative of Dr. Andrew Prentice analyzed all the energy expenditure data on babies and young children that had been obtained with this method (15). When the data were reduced to a per $\mathrm{kg}$ body weight basis, there was remarkable agreement between the different data sets. The results are summarized in Figure 2, which also includes an increment for the energy content of "new" tissue.

In fact, these data produced estimates for the dietary energy expenditure of young infants during the first 6 mo of life that were not so different from the impressions about intake that Alison Paul and I (Fig. 3) had earlier gained from our analysis of the food consumed by similar children (10). When the energy content of the newly deposited tissue was added to the measured energy expenditures and expressed on a per kg body weight basis, the total fell from around $115 \mathrm{kcal}(480 \mathrm{~kJ}) / \mathrm{kg} / \mathrm{d}$ at 1 mo to approximately $95 \mathrm{kcal}(400 \mathrm{~kJ}) / \mathrm{kg} / \mathrm{d}$ at $4 \mathrm{mo}$ and 85 $\mathrm{kcal}(355 \mathrm{~kJ}) / \mathrm{kg} / \mathrm{d}$ at $6 \mathrm{mo}$.

Once again, however, the UK committee, of which this time I was the chairman, was reluctant to make such sweeping changes to our estimated average energy requirements for children so young. I think in most contexts our reasoning was right. We were using a method for defining energy expenditure that was relatively new, and I have already identified myself with the philosophy of erring on the side of caution when defining RDA or DRV. Furthermore, DRV tend to be applied directly to infant feeding much more than to diets eaten by older children. They are used almost prescriptively and as a guide to how much infant formula or subsequent weaning foods a child should be given at different stages during infancy.

\section{THE SPECIAL CASE OF USING ENERGY EXPENDITURE DATA FOR ASSESSING ADEQUACY OF BREAST-FEEDING}

If one is not concerned with prescribing a diet, but with assessing the likely adequacy of a given intake of breast milk,

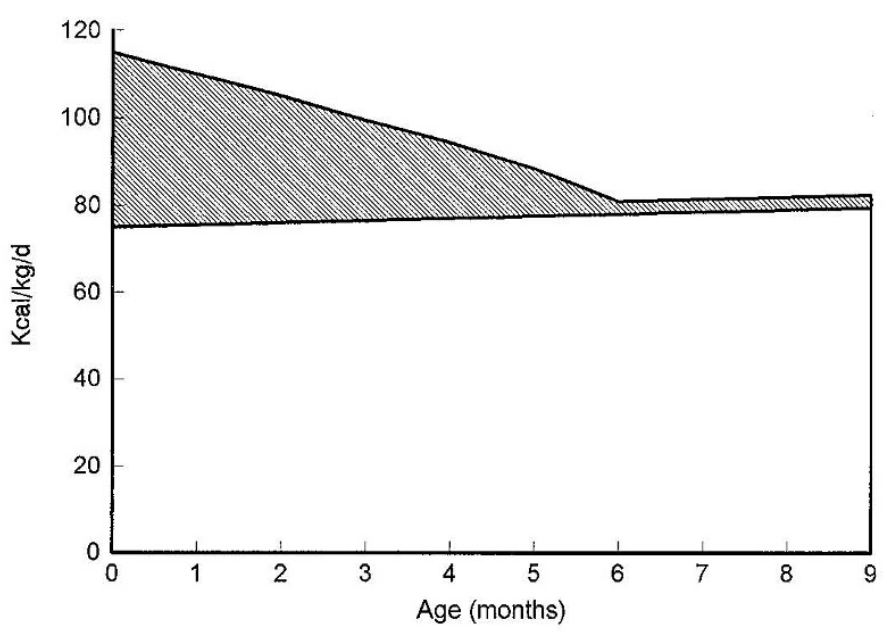

Figure 2. Energy requirements $0-9$ mo. Estimates of energy requirements derived by adding the energy deposited during growth (cross-hatched area) to a smooth curve for energy expenditure computed from doubly labeled water (14).

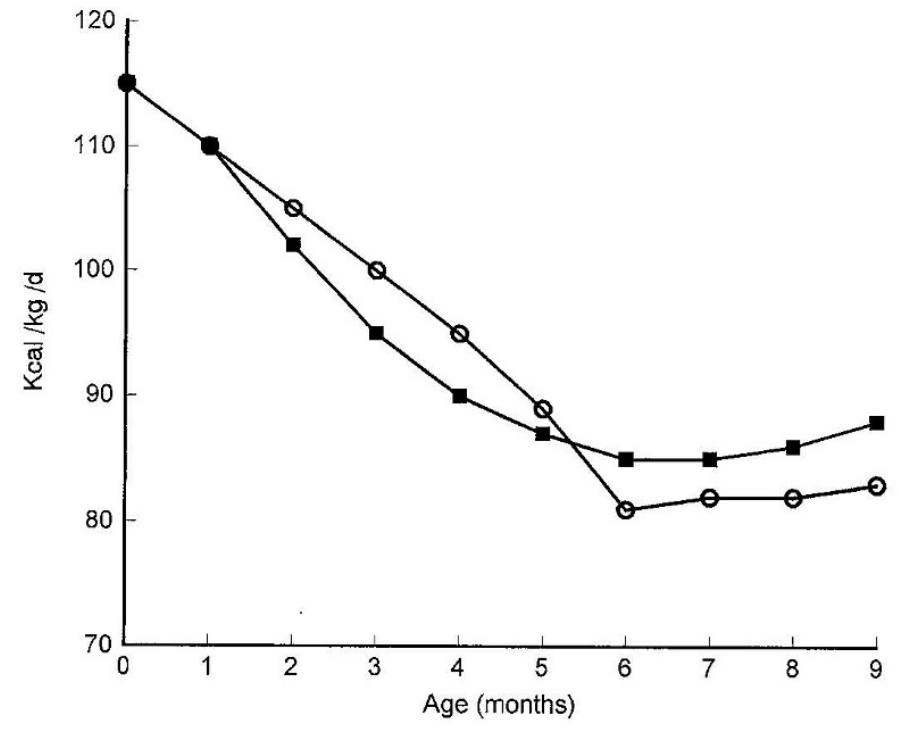

Figure 3. Energy needs for young babies predicted from doubly labeled water (15) (O) and food intake data (11) (a)

it does not make sense to include these precautionary increments. Accordingly, if one were to use the unmodified energy expenditure data derived from the doubly labeled water method discussed above, the average amount of energy required at 2,3, and 4 mo would now only be approximately $540 \mathrm{kcal}(2260$ $\mathrm{kJ}), 570 \mathrm{kcal}(2385 \mathrm{~kJ})$, and $606 \mathrm{kcal}(2535 \mathrm{~kJ})$. This calculation again assumes the baby is of average size and growing along the 50th weight percentile. Using this approach, we now have a guideline for the energy requirements of young babies that is much more compatible with the rule of thumb breastfeeding advice that has been given by pediatricians for decades (Fig. 4).

Although breast-feeding is the ideal for all young babies, wherever they live, it is absolutely necessary for the health and survival of the majority of children in the Third World. Because the average baby in the Third World tends to be a little smaller than its European counterpart, being born weighing approximately $3.0 \mathrm{~kg}$ and then tending to grow along the 25 th percentile rather than the 50 th, it is worthwhile redoing the calculation for a 25 th-percentile child. In this case, the 2-mo

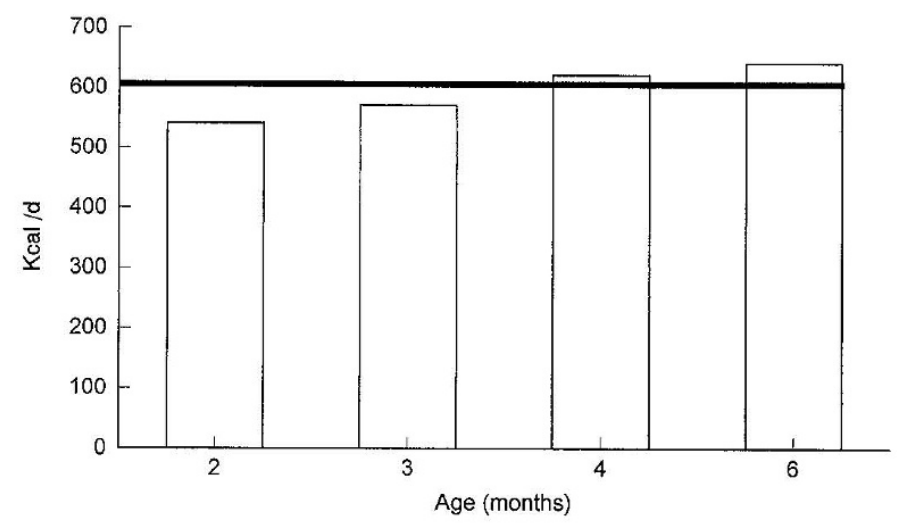

Figure 4. Energy needs of babies growing along the 50th percentile, calculated using doubly labeled water data. Eight hundred fifty $\mathrm{mL}$ of breast milk contain up to $600 \mathrm{kcal}(2510 \mathrm{~kJ})$. 
energy requirement estimate would be $500 \mathrm{kcal}(2095 \mathrm{~kJ}) / \mathrm{d}$, the 3-mo estimate approximately $520 \mathrm{kcal}(2175 \mathrm{~kJ})$, the 4-mo estimate $540 \mathrm{kcal}(2260 \mathrm{~kJ})$, and the 6 -mo estimate only approximately $590 \mathrm{kcal}(2470 \mathrm{~kJ})$. The adequacy of the 850 $\mathrm{mL}$ of breast milk would remain sufficient for such a child at 4 mo even if its energy concentration was nearer $60 \mathrm{kcal}(250$ $\mathrm{kJ}) / 100 \mathrm{~mL}$ than $70 \mathrm{kcal}(293 \mathrm{~kJ}) / 100 \mathrm{~mL}$. Some will criticize me for basing my calculations on a peak population average milk output of only $850 \mathrm{~mL} / \mathrm{d}$. They will say that this value could increase to very much higher values if only the mother would persevere as the going starts to get tough. It is true that some mothers routinely produce much more milk than this, especially those with twins. Nevertheless, measured intakes indicate that $850 \mathrm{~mL}$ is a reasonable average. It would be unwise to assume a greater peak milk output than this without new factual data to support an alternative approach.

\section{ONSET OF THE WEANING PROCESS}

There is a second outcome of practical importance arising from what I have been trying to do: placing traditional pediatric advice on a quantitatively sound basis. Current energy expenditure data do not allow much leeway for the average child beyond 3-4 mo. Around this time, there is an increasing likelihood that breast milk supplies alone may not be sufficient to cover all a baby's needs.

At the level of the individual, however, it would be ridiculous to try to predict exactly when the onset of the weaning period should start. There are so many variables that have to be taken into account: the size of the baby, the volume of milk its mother can produce, and the degree of interaction that exists between these two key factors, to name but a few.

Regardless of these complexities, it remains desirable for a mother to continue breast-feeding even when the need to introduce additional modes of feeding is clearly justified. In our own culture, this often coincides with a rapid decline in the number of breast-feedings per day, but there is no real reason why it should. In Third World societies, it is especially important that breast-feeding does not cease abruptly. Here the nutritional quality of most traditional weaning foods is far worse than that of the commercial foods taken for granted in the West. Even in the second year of life, it is by no means unusual for a mother to give her baby approximately $500 \mathrm{~mL}$ of breast milk each day. It is inconceivable that a child from a poor family would have access to alternative foods with such good nutritional quality. The balance of the child's overall diet is totally dependent on this breast milk.

\section{CONCLUSION}

The study of infant feeding, and the determination of the optimal way the baby's nutritional health can be safeguarded, represents a continuing challenge. In this review, I have limited the scope to a consideration of satisfying dietary energy needs. Clearly, there is a lot more to infant nutrition than just this. I hope, however, that I have stimulated younger investigators to tackle some of the more complex issues.

\section{REFERENCES}

1. Whitehead RG, Paul AA 1981 Infant growth and human milk requirements: a fresh approach. Lancet 2:161-163

2. WHO/FAO 1973 Energy and protein requirements. World Health Organization Technical Report Series No. 522. Food and Agriculture Organization Nutrition Meetings Report Series No. 52

3. Department of Health and Social Security 1969 Recommended intakes of nutrients for the United Kingdom. Reports on public health and medical subjects, No. 120. Her Majesty's Stationery Office, London

4. Whitehead RG 1977 Infant feeding in the developing world. Core J Paediatr 18:A3-A7

5. Waterlow JC, Thomson AM 1979 Observations on the adequacy of breast feeding. Lancet 2:238-242

6. Buss DH, Voss WR 1971 Evaluation of four methods for estimating the milk yield of baboons. J Nutr 101:901-909

7. Coward WA, Sawyer MB, Whitehead RG, Prentice AM, Evans J 1979 New method for measuring milk intakes in breast-fed babies. Lancet 2:13-15

8. Orr-Ewing AK, Heywood PF, Coward WA 1986 Longitudinal measurements of breast-milk output by the ${ }^{2} \mathrm{H}_{2} \mathrm{O}$ tracer technique in rural Papua New Guinean women. Hum Nutr Clin Nutr 40C:451-467

9. Department of Health and Social Security 1979 Recommended daily amounts of food energy and nutrients for groups of people in the United Kingdom. Reports on health and social subjects, No. 15. Her Majesty's Stationery Office, London

10. World Health Organization 1985 Energy and protein requirements. Report of joint FAO/WHO/UNU meeting. World Health Organization WHO Technical Report Series, No. 724, Geneva

11. Whitehead RG, Paul AA, Cole TJ 1981 A critical analysis of measured food energy intakes during infancy and early childhood in comparison with current international recommendations. J Hum Nutr 35:339-348

12. Whitehead RG, Paul AA 1988 Diet and growth in healthy infants. Hong Kong Paediatr 5:1-20

13. Coward WA, Cole TJ 1991 The doubly labelled water method for the measurement of energy expenditure in humans: risks and benefits. In: Whitehead RG, Prentice A (eds) New Techniques in Nutritional Research. Bristol-Myers Squibb/Mead Johnson Nutrition Symposia Series, Vol 9. Academic Press, New York, pp 139-176

14. Department of Health 1991 Dietary reference values for food energy and nutrients for the United Kingdom. Reports on health and social subjects, No. 41. Her Majesty's Stationery Office, London

15. Prentice AM, Lucas A, Vasquez-Velasquez L, Davies PSW, Whitehead RG 1988 Are current guidelines for young children a prescription for overfeeding? Lancet 2:10661069 